\title{
Matchmaking in Learning Networks: Bringing Learners Together for Knowledge Sharing
}

Citation for published version (APA):

Kester, L., Van Rosmalen, P., Sloep, P., Brouns, F., Koné, M., \& Koper, R. (2006). Matchmaking in Learning Networks: Bringing Learners Together for Knowledge Sharing. Interactive LearnIng Environments, 15(2), 117126. https://doi.org/10.1080/10494820701332663

\section{DOI:}

$10.1080 / 10494820701332663$

Document status and date:

Published: 21/08/2006

Document Version:

Peer reviewed version

Please check the document version of this publication:

- A submitted manuscript is the version of the article upon submission and before peer-review. There can be important differences between the submitted version and the official published version of record. People interested in the research are advised to contact the author for the final version of the publication, or visit the DOI to the publisher's website.

- The final author version and the galley proof are versions of the publication after peer review.

- The final published version features the final layout of the paper including the volume, issue and page numbers.

Link to publication

\section{General rights}

Copyright and moral rights for the publications made accessible in the public portal are retained by the authors and/or other copyright owners and it is a condition of accessing publications that users recognise and abide by the legal requirements associated with these rights.

- Users may download and print one copy of any publication from the public portal for the purpose of private study or research.

- You may not further distribute the material or use it for any profit-making activity or commercial gain

- You may freely distribute the URL identifying the publication in the public portal.

If the publication is distributed under the terms of Article 25fa of the Dutch Copyright Act, indicated by the "Taverne" license above, please follow below link for the End User Agreement:

https://www.ou.nl/taverne-agreement

Take down policy

If you believe that this document breaches copyright please contact us at:

pure-support@ou.nl

providing details and we will investigate your claim.

Downloaded from https://research.ou.nl/ on date: 26 Apr. 2023 
Running head: Matchmaking in Learning Networks

Matchmaking in Learning Networks: Bringing Learners Together for Knowledge Sharing Liesbeth Kester, Peter van Rosmalen, Peter Sloep, Francis Brouns, Malik Koné and Rob

$$
\text { Koper }
$$

Open University of the Netherlands, Heerlen, the Netherlands

Correspondence concerning this article should be addressed to Dr. Liesbeth Kester, Open University of the Netherlands, Educational Technological Expertise Centre, P.O. Box 2960, 6401 DL Heerlen, The Netherlands. Telephone: +31 (0)45-5762428. Email:

liesbeth.kester@ou.nl 


\begin{abstract}
In this article we describe a system that matches learners with complementary content expertise in reaction to a learner-request for knowledge sharing. It works through the formation of ad hoc, transient communities, that exist for a limited period of time and stimulate learners socially to interact. The matchmaking system consists of a request module, a population module and a community module, all supported by a database that contains learning content, learner information and output of the system. The request module allows the learner to type in a request, the time span in which an answer should be provided and the content it is related to. The population module selects suitable learners to populate the community by determining their content competence, sharing competence, eligibility and availability. MOODLE is used to host the community. A first experiment is briefly described that shows that content competence can be successfully determined using our method. Future experiments are discussed that aim at establishing the feasibility of the overall design.
\end{abstract}

Keywords: knowledge sharing, learning communities, social interaction 
Matchmaking in Learning Networks: Bringing Learners Together for Knowledge Sharing

In its broadest form, learning networks are defined as the experiences of students and teachers with the use of computers in learning (C-SALT, 2001). More specifically, learning networks are considered to 'use computer-mediated communication to support the delivery of courses in which anytime, anywhere access to interactions among the students and between the instructor/facilitator and the students are key elements' (Hiltz, Alavi, \& Dufner, 2004 (p. 1); Harasim, Hiltz, Teles, \& Turoff, 1995). In our view a Learning Network (LN) can be set apart from the learning networks defined earlier in that they are self-organizing and give rise to lifelong learning (Koper, Rusman, \& Sloep, 2005; Koper \& Sloep, 2002). This does not mean that social interaction and learning are supposed magically to occur. Rather it emphasises that the social structures that are conducive to or even needed for learning, emerge on top of a responsive, sophisticated, yet non-imposing technical infrastructure that guides self-organization and thus allows the Learning Network Users (LNUs) to develop their own preferred modes of interaction .

In LNs, LNUs are stimulated to create their own learning activities, build their own learning plans, and share their learning activities and their plans with peers and institutions. This self-directedness, however, may easily turn into isolation. LNUs who do not feel a sense of belonging with respect to a particular LN, are unlikely to interact with their peers, i.e. are unlikely to experience even a modicum of social interaction. Similarly, LNUs who do not feel engaged or committed are less likely to initiate an interaction with others, decreasing the sociability of the network as a whole. All this could be problematic since research shows that individual success or failure on a learning activity depends on the extent to which learners perceive themselves to be outsiders or insiders of a network (Wegerif, 1998). So, without a technical infrastructure that invites social interaction and guides self-organization within a 
$\mathrm{LN}$, problems will arise that could hamper the academic achievement of its users.

In this article we describe a system that matches LNUs with complementary content expertise. It works through the formation of so called ad hoc, transient communities. They are communities that (1) exist for a limited period of time, (2) specifically to fulfill the goal of knowledge sharing. This system supports the social embedding of LNUs in the LN and stimulates the LNUs socially to interact by sharing knowledge.

Theoretical basis of the matchmaking system for knowledge sharing A survey of the literature (see Kester, Sloep, Brouns, Van Rosmalen, De Vries, De Croock, \& Koper, 2006) yields three important conditions that should be met in order to enable knowledge sharing and learning in communities; we will summarise them here. First, to facilitate cooperation or collaboration in a community, clear boundaries and a clear set of rules that can be monitored and sanctioned within the community are required (the boundary condition) (Kollock \& Smidt, 1996). Furthermore, to assure the liveliness of a community, it should be populated with a heterogeneous group consisting of, for example, veterans and newbies or lurkers and posters (the heterogeneity condition) (Preece, Nonneke, \& Andrews, 2004). Also, for the social embedding of LNUs, one should establish recognisability of users, a historical record of actions, and continuity of contact (the accountability condition) (Kollock, 1998).

\section{The boundary condition}

To meet the boundary condition, ad hoc, transient communities should have a clear goal. Usually, this is triggered by a request of a LNU, for example, a content related question. The goal forms the incentive for the process of knowledge sharing. Indirectly, this goal strongly influences the degree of social interaction during knowledge sharing within the community. Clearly, a goal that can be reached by only one correct solution will elicit less social interaction than a goal that can be reached through various solutions. Different 
interaction-structures can be implemented to mediate the effects of a goal on the social interaction. For example, if the goal of the ad hoc, transient community can be reached by a limited number of solutions then a peer-tutoring structure could stimulate social interaction. King, Staffieri, and Adelgais (1998) advocate a three-step structure that consists of communication guidelines (i.e., listening, encouraging and giving feedback), an explanation procedure (i.e., the TEL WHY-procedure; telling in one's own words, explaining why and how, and linking of content), and questioning guidelines (e.g., asking comprehension questions or thinking questions). Other examples of structuring interaction within groups are “...'Group Investigation' (Sharan \& Sharan, 1992), 'Student Teams Achievement Division' (Slavin, 1995), 'Jigsaw' (Aronson \& Thibodeau, 1992; Bielaczycs, 2001), 'Structural Approach' by Kagan (1994)) (each structure is a scenario to teach specific skills and, although not likewise articulated, it is implicitly assumed that no situation is identical), 'Progressive Inquiry' (Rahikainen, Lallimo, \& Hakkarainen, 2001), the use of scripts (O'Donnell, 1999; Weinberger, Fischer, \& Mandl, 2001), scenarios that prescribe collaboration activity (Wessner, Pfister, \& Miao, 1999), feedback rules or requirements of a minimum degree of contributions to a discussion (Harasim, 1993; Harasim et al., 1995).” (Strijbos, 2004; p.33). From our perspective, 'high-structuring' methods such as peer-tutoring or Jigsaw are most suitable for goals that can be reached by a limited number of solutions because they guarantee a minimum degree of social interaction. 'Low-structuring' methods such as Progressive Inquiry, however, are most suitable for goals that can be reached by various solutions because these methods support rather than elicit social interaction (e.g. negotiation, argumentation), which is believed to be necessary under these circumstances.

The heterogeneity condition

To guarantee that the heterogeneity condition is met each ad hoc, transient community consists of a mix of LNUs with complementary expertise, all related to the goal of the 
community. So if, for example, 'answering a content related question' is the goal of the ad hoc, transient community, it should consist of LNUs with different levels of expertise related to the content-question since heterogeneity in levels of expertise can have differential effects on learning. Although King and colleagues (1998) found that peer-tutors do not necessarily have to be more competent or more knowledgeable than their tutee counterparts, a study of Hinds, Patterson, and Pfeffer (2001) indicates that tutors equal in competence convey qualitatively different knowledge than more distant tutors. The near tutors - those who are similar to their tutees in expertise level - use more concrete statements during their interactions with the tutee. In contrast, the distant tutors - those with a higher level of expertise - convey more abstract and advanced concepts. Heterogeneity in level of expertise between LNUs thus leads to a wide spectrum of knowledge shared in the community.

\section{The accountability condition}

The recognisability of users is ensured by forbidding the use of aliases such as screen names; this seems a reasonable demand to make in the context of a network devoted to learning. If one does not want to be this strict, users that go by a pseudonym should adopt one and only one persistent pseudonym, i.e. a singly pseudonym they keep throughout their membership of the LN and use in all interactions.

A historical record of user activities is maintained by logging all LNU-activities. The ones most significant for knowledge sharing - activities that reflect content competence and sharing competence - become part of an LNU's e-portfolio. Content competence reflects the LNU's mastery of the content within the LN. Hereto, the e-portfolio contains the products that resulted from the learning activities of a LNU (i.e., articles, reports, assessments). Sharing competence refers to the ability of a LNU satisfactorily to support peers during a process of knowledge sharing. This information could be acquired by letting LNUs rate each other's performance in the ad hoc, transient communities. The e-portfolio also incorporates this 
information. To enhance individual accountability (Slavin, 1995), both content and sharing competence of a LNU is made visible to the members of a particular ad hoc, transient community (there seems to be no reason to stigmatise a person at this stage by making it always available within the entire LN). For the same reason, rating should not be anonymous, at most singularly and persistently pseudonymous.

Continuity of contact during the ad hoc community's short lifetime is guaranteed by the interaction-structure that is implemented in them (see the boundary condition). Furthermore, these communities continuously surface in the LN to serve different purposes and although they continuously change with regard to composition, LNUs are likely to meet again.

The matchmaking system for knowledge sharing

The primary goal of the matchmaking system is to identify matching LNUs so as to populate the ad hoc, transient communities in reaction to a particular LNU-request for knowledge sharing. It should be web accessible (for easy access) and modular (for easy extensibility). For the latter reason, open source systems are preferable. The system consists of three functional units: the request module, the population module and the community module, all supported by a database (cf. Figure 1). The database contains learning content (e.g., documents) organized in courses, LNU information (e.g., completed courses, current courses, activities, calendar) and output of, among others things, the matchmaking system.

$$
<<\text { Insert Figure } 1 \text { about here }>>
$$

\section{The request module}

The Modular Object-Orientated Dynamic Learning Environment (MOODLE;

http://www.moodle.org) is used for the request module. Trough it each LNU can pose his or her request(s). The request module interface allows the LNU to type in, for example, a content 
related question, the time span in which an answer should be provided and the content the question is related to. These data are stored in the database. Simultaneously, MOODLE activates another system that uses Latent Semantic Analysis (LSA) to map the content question on the available documents in the database (Van Rosmalen, Sloep, Kester, Brouns, De Croock, Pannekeet, \& Koper, submitted; Van Bruggen, 2004). The LSA-system outputs (1) correlations between the question and (fragments of ) the documents in the database and (2) text fragments related to the content question. These data are also stored in the database for later use.

The population module

PHP is used to program the population module that selects suitable LNUs to populate the ad hoc, transient community. This selection process consists of four steps: (1) determine the content competence of a LNU, (2) determine the sharing competence of a LNU, (3) assure the heterogeneity of the community population and (4) determine the availability of the LNU.

Determine content competence. To determine the content competence of LNUs, first documents that are most relevant to the question are selected from the database. Relevance is expressed as a question-document correlation, which is determined through LSA. Beforehand, the lowest correlation that will be allowed and the maximum number of documents that will be retrieved, are set. For each document thus found, it is determined to which course or courses it belongs. The user database now reveals whether (1) a particular LNU has completed each course that LSA identified as being relevant to the question, (2) the time it took that LNU to complete each relevant course. and (3) how long ago each relevant course was completed by that LNU. These data yield a measure that indicates a LNU's course competence. For each LNU this course competence weighted by the question-course correlation yields his or her content competence.

Determine sharing competence. The sharing competence is related to the expertise of a 
LNU as a contributor in ad hoc, transient communities and/or to a peer-rating of his/her contribution quality. The weight of these measures is set beforehand. The sharing expertise is expressed by the relative number of contributions made by a LNU. It is calculated by dividing the number of contributions a LNU makes in an ad hoc, transient community by the total number of contributions made by all LNUs in this community. At the break-up of a community each participating LNU rates the quality of the other LNUs' contributions. A weighted combination of sharing expertise as well as the peer-rating expresses the sharing competence.

Ensure heterogeneity of the community population. The heterogeneity of the community is ensured by comparing the completed and not completed courses of the request submitting LNU - his or her 'portfolio' - to that of the other LNUs. From the database it is retrieved (1) which courses have and have not been completed by the LNUs and (2) which courses are relevant for the request. LNUs who did not complete any relevant course are ignored. For the other LNUs, the similarity between their portfolio and that of the requester is calculated. It is assumed that the more similar their portfolios are, the more equal their level of expertise, and conversely.

Determine the availability of the $L N U$. The availability is related to the past contributor load of a LNU in ad hoc, transient communities and/or to the available time of a LNU. The weight of these measures is set beforehand. The past contributor load is expressed by a combination of the relative number of communities a LNU has been involved in and the peer-rating of his/her contributions in these communities. The available time of a LNU is retrieved from the database and compared to the time span in which a contribution should be provided (i.e., input from the request module). A weighted combination of the past contributor load and available time expresses the availability of a LNU.

Based on the four measures described above, suitable LNUs can be selected to 
populate the ad hoc, transient communities. At least two LNUs are selected: the requester, and at least one 'expert' LNU. Although, common sense tells us that the group size of the community should not be too large (about 5 LNUs?) the cooperative learning literature does not provide specific guidelines on how to determine the optimal group size. Most of the time no distinction is made between interaction patterns for dyads, small groups (three to six members), and large groups (seven or more members) although the interaction patterns may differ (Strijbos, Martens, \& Jochems, 2004). However, since the number of inactive group members (i.e. lurkers) increases as group size increases (because of the lessened individual accountability of the group members), the effect of the increased group size on the interaction patterns of the active members may indeed be negligible (Kollock \& Smidt, 1996).

\section{The community module}

MOODLE is used to host the community. MOODLE is a full-blown virtual learning environment of which for the present purposes only the communication tools are relevant (the request module is a purpose built MOODLE extension). MOODLE offers both a forum and a wiki. The strength of a forum is that it enables its users to discuss specific topics, organized in threads. So each thread covers a separate topic and the threads usually branch off in subtopics. The history of the discussion can be traced by following a thread from origin to end. A wiki enables users jointly to work on a specific document (joint editing). Wikis allow one to follow the document history because they record the edits, including their time and author.

So both tools thus can be used to trace back the history of a discussion. For our purposes, however, the joint editing that a wiki facilitates, is an important asset. Admittedly, LNUs willing to share their knowledge could do so through a forum. But then they would each have to write up an answer to the question asked. Also, it would be up to the requester to make sense of all the answers and select what suits him or her best. Interaction with the LNUs 
providing the answer can only be done through commenting in the threads. In a wiki, however, the LNUs answering the question comment by editing each others answers. Thus they will arrive at the best answer as a collective. The LNU asking the question now does not have to filter the disparate information offered in the various threads, but can focus on one single answer. He or she can still comment, but it is also possible to rephrase the original question and even reformulate the answer in order to find out whether it was understood properly. A wiki also is to be preferred over a forum because the filtering of the information that is shared with the person who asked the question, is done by those who themselves share. And clearly, they are in a better position to do so than the person asking the question. At the start, the wikis are fed with text fragments by the LSA system to support the LNUs who were invited to participate in the community. In this way, the suitable LNUs do not have to start from scratch formulating an answer to a particular request.

\section{Discussion}

We have discussed the design of a system for asymmetrical knowledge sharing in a LN. Paramount in our discussion was the necessity to meet the boundary condition, the heterogeneity condition and the accountability condition to assure the thriving of the ad hoc, transient communities. These conditions we derived from a consideration of the extant literature.

In a first experiment (Van Rosmalen, Sloep, Brouns, Kester, Koné, \& Koper, in press), the LSA system (see Determine content competence) was calibrated and tested. It was found that $75 \%$ of the questions could be matched to a particular content. Moreover, for $40 \%$ of the questions, one or more text fragments could be identified that on the face of it seemed useful for formulating an answer in the wikis. This paves the way for successfully populating ad hoc, transient communities. 
Experiments are planned to establish the feasibility of the overall design. They will focus on the calibration and testing of the suitability measure (content competence, sharing competence, heterogeneity and availability). For example, we have to determine a working combination of weights of the suitability ranking.

In a later phase, we will take a closer look at the boundary, heterogeneity, and accountability conditions described earlier. We will investigate peer tutoring as one specific kind of knowledge sharing (the boundary condition): Does a peer-tutoring structure fit the knowledge sharing goal 'answering a content related question', and does it improve knowledge sharing? Subsequently, we will take a closer look at a composition of the ad hoc, transient community that best facilitates knowledge sharing (the heterogeneity condition): What is the optimal group size for an ad hoc, transient community, and does a mix of community members with different levels of expertise indeed lead to a wide spectrum of knowledge shared by the community? Next, experiments will be carried out that focus on learner-representations in the LN (the accountability condition): How do we guarantee the social presence of LNUs in the LN, and does an e-portfolio that contains the history of content competence and sharing competence provide enough information to ensure accountability?

The results of all these experiments will allow us both to optimize the present infrastructure and to inform our considerations of how to use the infrastructure for other, more generalized knowledge sharing activities.

\section{References}

Aronson, E. \& Thibodeau, R. (1992). The Jigsaw classroom: A cooperative strategy for an educational psychology course. In J. Lynch, C. Modgil, \& S. Modgil (Eds.), Cultural diversity and the schools (pp. 231-256). Washington: Palmer.

Bielaczycs, K. (2001). Designing social infrastructure: The challenge of building computer- 
supported learning communities. In P. Dillenbourg, A. Eurelings, \& K. Hakkarainen (Eds.), European perspectives on computer-supported collaborative learning: Proceedings of the 1st European conference on computer-supported collaborative learning (pp. 106-114). Maastricht: Maastricht University.

C-SALT (2001). Networked learning in higher education. Retrieved 01/06/2005 from http://csalt.lancs.ac.uk/jisc/.

Harasim, L. (1993). Collaborating in cyberspace: Using computer conferences as a group learning environment. Interactive Learning Environments, 3, 119-130.

Harasim, L., Hiltz, R., Teles, L., \& Turoff, M. (1995). Learning Networks: A field guide to teaching and learning online. Cambridge: MIT Press.

Hiltz, S. R., Alavi, M. and Dufner, D. (2004) Asynchronous Learning Networks (“ALN's”) for E-Learning: Priorities for Future Software Development. Panel Discussion, Conference on Human Factors in Computing Systems, Special Interest Groups (SIGs), SIGCHI ACM, April 24-29, Vienna, Austria.

Hinds, P. J., Patterson, M., \& Pfeffer, J. (2001). Bothered by abstraction: The effect of expertise on knowledge transfer and subsequent novice performance. Journal of Applied Psychology, 86, 1232-1243.

Kagan, S. (1994). Cooperative learning. San Juan Capistrano: Kagan Cooperative Learning.

Kester, L., Sloep, P., Brouns, F., Van Rosmalen, P., De Vries, F., De Croock, M. \& Koper R. (2006). Enhancing Social Interaction and Spreading Tutor Responsibilities in BottomUp Organized Learning Networks. Proceedings of the International Conference Web Based Communities, San Sebastian, Spain.

King, A., Staffieri, A., \& Adelgais, A. (1998). Mutual peer tutoring: Effects of structuring tutorial interaction to scaffold peer learning. Journal of Educational Psychology, 90, 134-152. 
Kollock, P. \& Smith, M. (1996). Managing the virtual commons: Cooperation and conflict in computer communities. In S. Herings (ed.), Computer-mediated communication: Linguistic, social, and cross-cultural perspectives (pp. 109-128). Amsterdam: John Benjamins.

Koper, R., \& Sloep, P. B. (2002). Learning Networks connecting people, organizations, autonomous agents and learning resources to establish the emergence of effective lifelong learning. RTD Programma into Learning Technologies 2003-2008. More is different...Retrieved 01/06/2005 from http://hdl.handle.net/1820/65.

Koper, R., Rusman, E. \& Sloep, P. B. (2005). Effective Learning Network. Lifelong Learning in Europe IX, 18-28.

O'Donnell, A. M. (1999). Structuring dyadic interaction through scripted cooperation. In A. M. O’Donnell, \& A. King (Eds.), Cognitive perspectives on peer learning (pp. 179196). Mahwah, NJ: Lawrence Erlbaum.

Preece, J., Nonneke, B., \& Andrews, D. (2004). The top five reasons for lurking: Improving community experiences for everyone. Computers in Human Behavior, 20, 201-223.

Rahikainen, M., Lallimo, J., \& Hakkarainen, K. (2001). Progressive inquiry in CSILE enviroment: Teacher guidance and students engagement. In P. Dillenbourg, A. Eurelings, \& K. Hakkarainen (Eds.), European perspectives on computer-supported collaborative learning: Proceedings of the 1st European conference on computersupported collaborative learning (pp. 520-528). Maastricht: Maastricht University.

Sharan, Y. \& Sharan, S. (1992). Expanding cooperative learning through group investigation. New York: Teachers College Press.

Slavin, R. E. (1995). When does cooperative learning increase student achievement? Psychological Bulletin, 94, 429-445.

Strijbos, J. W. (2004). The effect of roles on computer-supported collaborative learning. Unpublished master's thesis, Open University of the Netherlands, Heerlen, the 
Netherlands.

Strijbos, J. W., Martens, R. L., \& Jochems, W. (2004). Designing for interaction: Six steps to designing computer-supported group-based learning. Computers and Education, 42, 403-424.

Van Rosmalen, P., Sloep, P., Brouns, F., Kester, L., Koné, M. \& Koper, R. (in press). Knowledge matchmaking in learning networks. Alleviating the tutor load by mutually connecting learning network users. British Journal of Educational Technology.

Van Rosmalen, P., Sloep, P., Kester, L., Brouns, F., De Croock, M., Pannekeet, K., \& Koper, R. (submitted). Alleviating the Tutor Load in Learning Networks.

Wegerif, R., Mercer, N., \& Dawes, L. (1998). Software design to support discussion in the primary curriculum. Journal of Computer Assisted Learning, 14, 199-211.

Weinberger, A., Fischer, F., \& Mandl, H. (2001). Scripts and scaffolds in problem-based CSCL environments: Fostering participation and transfer. In F. Fischer, \& H. Mandl (Eds.), Computer-mediated cooperative learning. Symposium conducted at the $9^{\text {th }}$ European Conference of the European Association for research on Learning and Instruction. 
Figure captions

Figure 1. An overview of the different modules in the matchmaking system in the form of a UML activity diagram. This diagram supposes that peer tutoring is used for knowledge sharing. The enclosed parts on the top left and bottom right (i.e., line) are the request and population modules respectively, the part in the top middle is the LSA module (i.e., dotted line). 
Figure 1

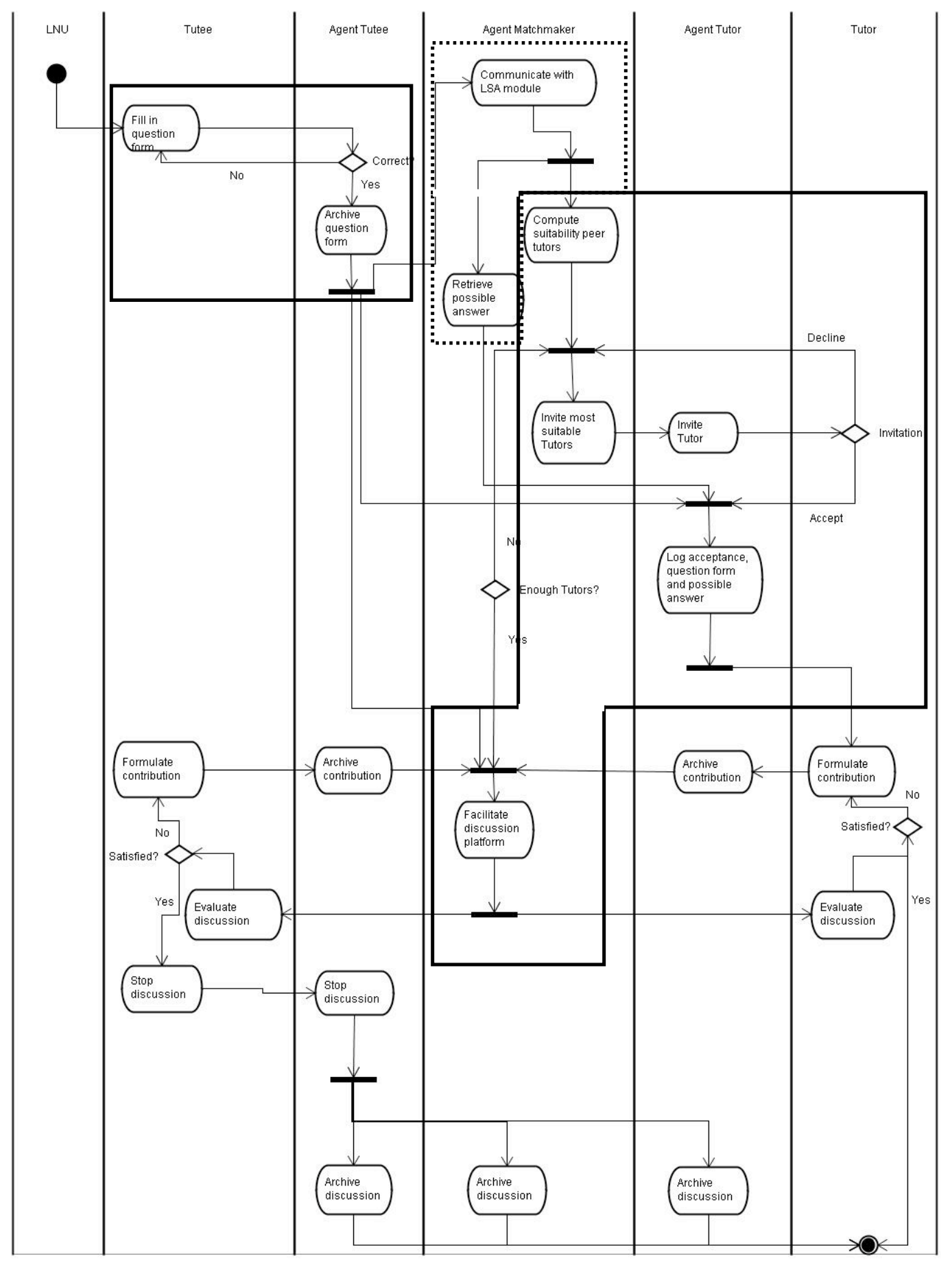

Bruggen, v., J., Sloep, P., Rosmalen, P., Brouns, F., Vogten, H., Koper, R., Tattersall, C. (2004). Latent semantic analysis as a tool for learner positioning in learning networks for lifelong learning.Unpublished manuscript. 